\title{
NEURAL NETWORK MODELING TO SUPPORT AN EXPERIMENTAL STUDY OF THE COMPOSTING PROCESS OF BIOWASTE WITH FILTER CAKE AND STAR GRASS
}

\author{
JONATHAN SOTO-PAZ ${ }^{1}$, PABLO MANYOMA-VELÁSQUEZ ${ }^{2}$, RICARDO OVIEDO OCAÑA ${ }^{4}$, \\ WILFREDO ALFONSO ${ }^{3}$, EDUARDO CAICEDO ${ }^{3}$ \& PATRICIA TORRES-LOZADA ${ }^{1}$ \\ ${ }^{1}$ ECCA Group.Faculty of Engineering, Universidad del Valle, Colombia \\ ${ }^{2}$ Logystic and Production Group, Faculty of Engineering, Universidad del Valle, Colombia \\ ${ }^{3}$ PSI Group, Faculty of Engineering, Universidad del Valle, Colombia \\ ${ }^{4} \mathrm{GPH}$ Group, Universidad Industrial de Santander, Colombia
}

\begin{abstract}
Biowaste (B) is the predominant fraction of municipal solid waste (MSW) in developing countries and composting is one of the most widely used technologies for the use of biowaste. Several interrelated factors affect the efficiency of the bioconversion of the substrate influencing the development of the composting process and therefore, the quality of the final product. Simulations through Artificial Neural Networks-ANN allows to determine the influence of these factors and to make predictions that improve the process and the quality of the final product which providing the definition of real criteria for the implementation of the technology. This study shows the feasibility of simulating, with feedforward ANN, the composting process at a pilot scale by mixing with biowaste, Filter cake (FC) and star grass (SG). Experiments were carried out with a Box-Bemkhen design, simultaneously evaluating factors such as the mixing ratio (MR) of B:FC:SG (60:20:20, 70:10:20 and 65:15:20) and turning frequency (TF) (1, 2 and 3 days were experimented) on variables such as temperature, $\mathrm{pH}$, oxidizable organic carbon and total nitrogen which also allowed to get heuristic models based on ANN. It was found that the MR and TF affect both the process and the quality of the product, presenting the best result at the ratio of $65: 25: 10$ with TF of 2 times per week which is supported by the ANN prediction with an $R^{2} \geq$ 0.85 according to the experimental data.

Keywords: simulation, co-composting, neuronal network, filter cake, biowaste, star grass.
\end{abstract}

\section{INTRODUCTION}

Biowaste in developing countries corresponds to the predominant fraction of municipal solid waste (MSW) [1], [2], characterized by a heterogeneous physical composition, high humidity, presence of salts, and deficiency organic carbon and nutrients as phosphorus [3], [4].

Traditionally, the biowaste final disposal has predominated as a management strategy in developing countries, particularly in Latin America and the Caribbean [5]. However, this method is questioned due to the associated with environmental impacts such as greenhouse gases (GHGs) and leachates generation [6]-[8]. One of the most application alternative for biowaste approach is the composting process, technology of low cost of investment, simple operation and with which obtained a product of added value, whose physicochemical and biological properties contribute to improve the availability of organic matter and nutrients in the soil [9].

In spite of the extensive research that has been carried out around the composting process for the control of environmental contamination and for obtaining a quality product, Onwosi et al. [10]; Cerda et al. [11] and Soto-Paz et al. [12] explain that it is still necessary to carry out investigative efforts to analyze operational factors and deepen a better understanding of the biochemical phenomena of the process. Several researchers have reported that operational factors such as the mixture ratio (MR) between a substrate and a co-substrate and the turning 
frequency (TF) influence the composting process and product quality. These factors contribute to solve biowaste physicochemical limitations by improving the aeration piles conditions, the substrate degradation rate and increase the nutrients content in the final product.

The use of amendment materials (AM) and bulking agents (BA) has been widely documented in biowaste composting. Filter cake (FC), which is by-product of the sugar cane industry with a high content of organic matter, phosphorus and moderate content of trace elements $(\mathrm{Ca}, \mathrm{Mg}, \mathrm{Fe})$ has been used as AM for cane bagasse composting [13]. The star grass $(\mathrm{SG})$, is a BA that provides fibre, carbon, regulates excess moisture, improve structure and aeration [14]. These materials can be mixed together with biowaste, for which it is crucial to find the region of MR where the benefit is maximized.

In manually operated composting facilities, the TF is the main aeration mechanism in the piles. Several authors have reported TF variations from six turning per week to one every two weeks [15]-[17]; however, others [18]-[20] emphasize that the process is benefited with TF between one and three turnings per week. In spite of this, the majority of research around the MR or TF only considers the incidence of a single factor on the process. Onwosi et al. [10] have pointed out that when a single study factor is involved, the reliability of results may not achieve a representation of reality due to the dynamics and complexity of the process, so they have suggested to study these factors together; this aspect was also observed by Kumar et al. [18] and Iqbal et al. [19].

Thus, the growing interest in the simultaneous study of two or more factors and their incidence on a response parameter has motived the construction of mathematical models from experimentation that allows making inferences about initial unintended conditions. Artificial Neural Networks (ANN) is a tool that identifies the dynamic relationships between factors [20], [21] and offers the advantages of identifying experimental failures and obtaining predictive models; all these aspects would improve the process and the final product quality in biowaste composting.

The aim this work is evaluate the effects of MR B:FC:SG and TF simultaneously through ANN as a computational model of biowaste composting, which have been preliminarily used in the composting of other types of substrates.

\section{METHODOLOGY}

\subsection{Physicochemical characterization of the substrate and amendment material} and bulking agents

A pilot-scale experiment was developed at the municipality of the department of VersallesValle del Cauca, Colombia, where the separation of the source and the selective collection of biowaste are practiced. A representative sample ( $2 \mathrm{~kg}$ each) was taken from each substrate (i.e. Biowaste, FC and ST). For this, the random quartering technique described by Sakurai [22] was followed. FC is extracted from the processing of sugarcane in a rural area sugar mill of this municipality. SG was obtained from the surrounding green areas of the composting facility. Samples were taken to the laboratory to perform analysis of: moisture, $\mathrm{pH}$, total organic carbon (TOC), total nitrogen (TN), total phosphorous (TP) and total potassium (TK). Analyses were performed using standard methods [23] and Colombian technical norm [24]. Table 1 shows the physicochemical characterization of the substrates. 
Table 1: Physicochemical characteristics of the substrate and co-substrates.

\begin{tabular}{llccc}
\hline Parameters & Method/technique & Biowaste & FC & SG \\
\hline Moisture (\%) & Gravimetric & $77.26 \pm 2.60$ & $65.50 \pm 2.14$ & $78.35 \pm 9.87$ \\
pH (uni) & Potentiometric & $5.54 \pm 0.34$ & $5.37 \pm 0.22$ & $7.52 \pm 0.48$ \\
TOC (\%) & Spectrophotometric & $31 \pm 2.5$ & $48.59 \pm 3.38$ & $37.84 \pm 5.81$ \\
TN (\%) & Titrimetric Kjeldahl & $1.45 \pm 0.13$ & $1.60 \pm 0.76$ & $1.64 \pm 0.68$ \\
TP & Spectrophotometric & $0.35 \pm 0.19$ & $0.97 \pm 0.07$ & $0.38 \pm 0.17$ \\
TK (\%) & Atomic absorption & $1.84 \pm 0.15$ & $0.15 \pm 0.01$ & \pm 0.11 \\
\hline
\end{tabular}

Table 2: Factors and treatments considered in the Box Behnken.

\begin{tabular}{|c|c|c|c|c|c|c|c|}
\hline \multirow{2}{*}{$\begin{array}{l}\text { Treatment } \\
{[\mathrm{X} 1, \mathrm{X} 2]}\end{array}$} & \multicolumn{2}{|c|}{ Factors } & \multicolumn{5}{|c|}{ Parameters } \\
\hline & *MR & $\mathrm{TF}$ & $\begin{array}{c}\text { Moisture } \\
(\%)\end{array}$ & pH (Unid) & VS (\%) & TOC (\%) & TN (\%) \\
\hline $1\left[\begin{array}{ll}-1 & -1\end{array}\right]$ & $65: 15: 20$ & 1 & $76.11 \pm 0.45$ & $5.98 \pm 0.47$ & $73.32 \pm 0.11$ & $31.36 \pm 8.93$ & $1.64 \pm 0.38$ \\
\hline $2\left[\begin{array}{ll}-1 & 0\end{array}\right]$ & $65: 15: 20$ & 2 & $75.38 \pm 1.72$ & $5.94 \pm 1.03$ & $75.92 \pm 0.38$ & $33.62 \pm 1.98$ & $1.32 \pm 0.71$ \\
\hline $3\left[\begin{array}{ll}-1 & 1\end{array}\right]$ & $65: 15: 20$ & 3 & $73.50 \pm 1.18$ & $6.14 \pm 0.88$ & $78.47 \pm 0.38$ & $31.17 \pm 3.67$ & $1.51 \pm 0.36$ \\
\hline $4\left[\begin{array}{ll}0 & -1\end{array}\right]$ & $60: 20: 20$ & 1 & $71.94 \pm 0.68$ & $6.26 \pm 0.46$ & $77.73 \pm 0.21$ & $37.16 \pm 4.10$ & $1.66 \pm 0.22$ \\
\hline $5\left[\begin{array}{ll}0 & 0\end{array}\right]$ & $60: 20: 20$ & 2 & $71.11 \pm 0.45$ & $6.19 \pm 0.12$ & $73.15 \pm 0.44$ & $34.64 \pm 5.81$ & $1.55 \pm 0.36$ \\
\hline $6\left[\begin{array}{ll}0 & 1\end{array}\right]$ & $60: 20: 20$ & 3 & $72.14 \pm 1.16$ & $6.28 \pm 0.35$ & $80.47 \pm 0.87$ & $38.74 \pm 2.58$ & $1.55 \pm 0.15$ \\
\hline $7\left[\begin{array}{ll}1 & -1\end{array}\right]$ & $70: 10: 20$ & 1 & $68.99 \pm 1.38$ & $6.33 \pm 0.37$ & $78.68 \pm 0.33$ & $40.92 \pm 2.38$ & $1.54 \pm 0.27$ \\
\hline $8\left[\begin{array}{ll}1 & 0\end{array}\right]$ & $70: 10: 20$ & 2 & $69.71 \pm 0.66$ & $6.45 \pm 1.32$ & $81.18 \pm 0.48$ & $45.35 \pm 6.23$ & $1.62 \pm 0.13$ \\
\hline $9\left[\begin{array}{ll}1 & 1\end{array}\right]$ & $70: 10: 20$ & 3 & $69.84 \pm 0.98$ & $6.57 \pm 0.64$ & $79.47 \pm 0.81$ & $43.54 \pm 2.90$ & $1.58 \pm 0.10$ \\
\hline
\end{tabular}

\subsection{Composting process: unit and experimental design}

The experimental unit-UE corresponds to composting piles of $150 \mathrm{~kg}$. The experimentation area has a roof and a level surface made of concrete. An experimental design type Box Behnken was applied to evaluate the simultaneous influence of two experimental factors: MR and TF; each factor had three study levels defined according to the specialized literature [11], [25]. Two criteria were considered to define the mixtures: (i) biowaste should be the predominant substrate; and (ii) $\mathrm{C} / \mathrm{N}$ ratio should be higher than 15 (i.e. mixtures were established using mass balances based on theoretical values for the substrates). Additionally, one, two and three days TF were evaluated [13], [18], [26]. The control treatment corresponding to a single biowaste pile and the TF applied varied according to the temperature changes [26]. All treatments were run in duplicates (two piles per treatment). Table 2 presents the levels and coding of the experimental design.

Based on the treatments of the experiment, the process was monitored in terms of response parameters such as temperature, $\mathrm{pH}$ TOC and TN. The measurement of these parameters was made every two days during the active phase of the process and during the cooling and maturation phase once a week. Two-way analysis of variance (ANOVA) was applied for significance determination for the entire composting matrix of the ten runs. For all analyses, the findings are considered for $\mathrm{p} \leqslant 0.05$ significance.

\subsection{Architecture of Neuronal Computational Model applicable to each response variable}

We chose a Multilayer Perceptron Artificial Neural Network architecture (MLP) feedforward with Bayesian regularization for its ability to successfully solve nonlinear dynamic 
problems through its supervised training [27]. The topology of the ANN corresponds to three (3) neurons in the input layer corresponding to the process time (PT), TF and MR and one (1) neuron in the output layer that corresponds to a response parameter (i.e. temperature, $\mathrm{pH}$, TOC and TN). The number of neurons in the hidden layer was determined by analyzing their predictability against the response parameters using as a performance metric the sum of the square errors (SSE), as shown in the eqn (1). The activation functions applied to the neurons of the hidden layer and the output layer were, sigmoidal and linear, respectively according to Wang and Wan [28]

$$
S S E=\sum_{j=1}^{n}\left(Y_{k j}-\hat{Y}_{k j}\right)^{2},
$$

where $Y_{k j}$ is the experimental data obtained from the $k$ th response parameter at the instant $j$ th; $Y_{k j}$ is the corresponding value estimated by the ANN under the same conditions and $n$ represents the number of experimental data. With the experimental data, a general adaptive neuronal model was generated to describe the behavior of the different response parameters. To validate the models as a function of each response parameter, the mean square error $\left(R^{2}\right)$ were used.

\subsection{Simulation of the composting process with ANN}

The neuronal model for each response variable was applied to get a non-linear adaptive interpolation, which allowed to make predictions over time on mixing proportions not considered in the experimental design and making inferences about the product quality.

\section{RESULTS AND DISCUSSION}

\subsection{Architecture of the ANN and Neuronal Model applicable to each variable response}

Fig. 1 presents the results obtained from the evaluation of different ANN responses over 50 runs per topology. It is observed that the ANN with six (6) neurons in the hidden layer presents a better performance with the lower values of SSE between 0.21-0.55 and MSE values between $0.019-0.05$, so the ANN shows potential to describe the evolution of the composting process of biowaste mixed with FC and SG.

Eqn (2) shows the general adaptive neuronal model that describes the evolution of composting process in function of a response parameter [28], [29]. Table 3 presents specific neuronal models for each response variable. Applying these models, it is possible to obtain the time value of a response variable for different experimental conditions (i.e. TF and MR).

$$
S \hat{Y}_{k j}=W_{Y_{k}}^{o} \cdot \mathrm{F}_{a c t}^{H}\left(\mathrm{~W}_{Y_{k}}^{H} \cdot X_{j}+\theta_{Y_{k}}^{H}\right)+\theta_{Y_{k}}^{o}
$$

where,

$\widehat{Y}_{k j} \quad$ represents the response parameter to a stimulus of the input pattern $X j$;

$W_{Y_{k}}^{o} \quad$ represents the matrix of the synaptic weights of the output layer of the ANN;

$\mathrm{F}_{a c t}^{H}(z) \quad$ is the sigmoidal tangent activation function represented as: $\mathrm{F}_{a c t}^{H}(z)=\frac{1-e^{-z}}{1+e^{-z}}$;

$\mathrm{W}_{Y_{k}}^{H} \quad$ represents the matrix of the synaptic weights of the hidden layer of the ANN;

$X_{j} \quad$ is the $j$ th pattern of the input vector such that: $X_{j}=\left[\begin{array}{lll}T P_{j} & F V_{j} & P M_{j}\end{array}\right]^{T}$;

$\theta_{Y_{k}}^{H} \quad$ represents the bias of the neurons of the hidden layer;

$\theta_{Y_{k}}^{o} \quad$ represents the bias of the neurons in the output layer. 


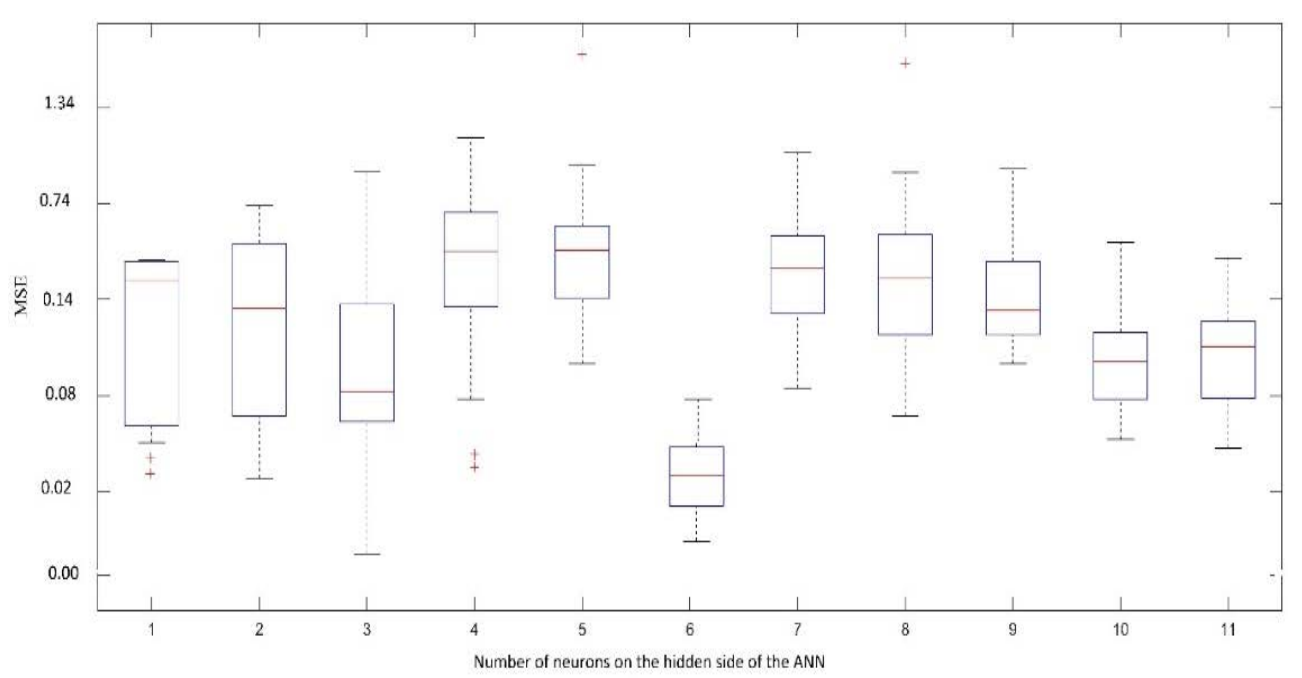

Figure 1: Topologies used for the best ANN selection.

\subsection{Simulation of the composting process with ANN}

Fig. 2 presents the simulations performed with the neural models for the three levels of MR evaluated corresponding to a TF. The duration of process varied according to the TF and the MR. At higher TF (i.e. three turning/week) the duration of the process was reduced by 10 days compared to treatments with lower TF (i.e. one turning/week) and in 6 days compared to a TF of two turning/week. Regarding MR, it was observed that MR between 22 and $28 \%$ stimulate biological activity and reduce the duration of process. This revealed that TF and MR have an interactive effect on the duration of process due to aeration conditions and nutrient balance [30]. Fig. 2(a)-(c) shows the temperature profiles with the four sequential phases of process for different simulation conditions, showing interaction between the MR and TF $(\mathrm{p} \leqslant 0.03)$. It is highlighted that all the treatments reached hygienic conditions because of fact that temperatures higher than $55^{\circ} \mathrm{C}$ was achieved for more than four consecutive days [25]. It is observed that increasing the volts allows to reach high temperatures (range of 55 and $67^{\circ} \mathrm{C}$ ) sustained between 12 and 16 days of process. The highest temperature is observed with the highest TF (i.e. three turning/week), reaching $67^{\circ} \mathrm{C}$ in 6 days. Under this condition, MR between 23 and 27\% allow temperatures of thermophile range of greater prolongation with respect to MR between 10 and $22 \%$. A similar situation was observed in TF of two turning/week with MR between 23 and 26\%, reaching temperatures of higher order than $54^{\circ} \mathrm{C}$. With the lowest $\mathrm{TF}$ (i.e. one turning/week), the temperature profiles was lower than those found under other conditions, denoting that a low applied TF compacted the piles contributing to limit the biological activity, reducing the generation of heat [31], [32]; However, if the MR (i.e. higher than 15\%) is increased, the porosity of the pile could also increase and influence so that the temperature may be higher. This observation has been reported by Ogunwande et al. [30] that indicate that increasing the $\mathrm{TF}$ and a $\mathrm{C} / \mathrm{N}$ ratio greater than 20 and less than 30 positively influence the development of the process, reflected in higher temperatures reached due to greater activity biological. 
Table 3: Parameters of the neuronal model $\left\{W_{Y_{k}}^{o} \cdot \frac{1-e^{-z}}{1+e^{-z}}\left(W_{Y_{k}}^{H} \cdot P T \quad T F V_{j} \quad M R_{j}+\right.\right.$ $\left.\left.\theta_{Y_{k}}^{H}\right)+\theta_{Y_{k}}^{o}\right\}$.

\begin{tabular}{|c|c|c|c|c|c|}
\hline$W_{Y_{k}}^{\circ}$ & \multicolumn{3}{|c|}{$\theta_{Y_{k}}^{\circ}$} & \multirow[t]{2}{*}{$W_{Y_{k}}^{H}$} & \multirow[t]{2}{*}{$\theta_{Y_{k}}^{H}$} \\
\hline Temperature & & & & & \\
\hline 9.8851 & -0.5579 & 1.5088 & 10.6797 & 2.8021 & \\
\hline-4.7406 & -31.946 & 3.2827 & -2.4536 & -0.1588 & \\
\hline-2.2772 & 0.6112 & -0.3533 & -1.0841 & 0.4329 & -0.6465 \\
\hline 8.5043 & -0.3452 & 0.7796 & 9.0132 & -6.1053 & \\
\hline 1.6248 & 0.598 & -0.4982 & 0.9308 & -0.7063 & \\
\hline 12.4006 & -0.1827 & 0.3739 & 12.6178 & 3.9966 & \\
\hline \multicolumn{6}{|l|}{$\mathrm{pH}$} \\
\hline 1.7323 & -1.6444 & -0.2358 & -0.2851 & 0.2511 & \\
\hline 0.4129 & 1.2312 & -0.0959 & -0.2281 & 0.3317 & \\
\hline-5.192 & -0.1314 & 0.5328 & -1.9189 & 0.2605 & -0.6207 \\
\hline-1.1236 & 1.2454 & 0.3318 & 0.9498 & -0.3007 & \\
\hline-6.1383 & 0.1025 & -0.0209 & -5.3933 & -3.5207 & \\
\hline 8.1248 & -0.1789 & -0.0026 & 6.6728 & -2.1989 & \\
\hline \multicolumn{6}{|l|}{ TOC } \\
\hline 0.2856 & -0.9031 & -0.7619 & 0.4061 & 0.3093 & \\
\hline-0.1238 & -0.9962 & -0.3528 & 0.1748 & -0.313 & \\
\hline-1.8079 & -1.122 & 0.6971 & -0.1755 & 0.1473 & 0.6576 \\
\hline 3.2042 & -0.0026 & -0.171 & 3.5931 & -1.5342 & \\
\hline 0.9589 & -0.18 & 0.7238 & 0.7341 & 0.7413 & \\
\hline-1.4979 & 0.0962 & -0.6062 & -0.4578 & 0.6643 & \\
\hline \multicolumn{6}{|l|}{$\mathrm{TN}$} \\
\hline-0.552 & 1.9088 & 0.2041 & -0.7315 & -1.4466 & \\
\hline 2.6908 & -0.0292 & 0.0877 & 1.6279 & 1.0323 & \\
\hline-0.3078 & -1.1584 & -1.1069 & 0.4942 & -1.7698 & 0.8183 \\
\hline 1.7115 & 0.121 & 0.0818 & 1.9145 & -1.1649 & \\
\hline 0.7781 & -0.8493 & -1.006 & 0.037 & 0.9977 & \\
\hline-0.8188 & 0.5257 & 2.1413 & -0.6206 & 12.786 & \\
\hline
\end{tabular}

In relation to the $\mathrm{pH}$, it was found that both the TF and the MR present interaction and influence the behavior of the $\mathrm{pH}(\mathrm{p} \leqslant 0.05)$. The initial values of this parameter was slightly acidic (i.e. between 6.12 and 6.53 units); all the conditions simulated from day 3 , values higher than 7.5 units was presented, and on day 7 they reached 8.3 units (Fig. 2(d)-(f)). Kalemelawa et al. [33] indicate that the $\mathrm{pH}$ increases to alkaline values mainly in the active phase of the process due to the decomposition of organic matter (OM), volatilization of $\mathrm{NH}_{3}$ and possible formation of $\mathrm{KOH}$ by the content of potassium in biowaste. The increase in $\mathrm{pH}$ values was also reported by Bryndum et al. [13] in the composting of poultry manure with filter cake. At the end of the process, values between 7.53 and 9.0 units was found. With MR between 23 and $27 \%$ in TF two and three turning/week, $\mathrm{pH}$ values between 7.5 and 8.1 promoted by more frequent flips were obtained. This was possibly due to the release of $\mathrm{H}^{+}$ ions product of the nitration process [34], [35]. The most alkaline $\mathrm{pH}$ values was obtained with the FV1 (one turning/week), showing that the $\mathrm{pH}$ is sensitive to the changes of aeration in the process [30]. 


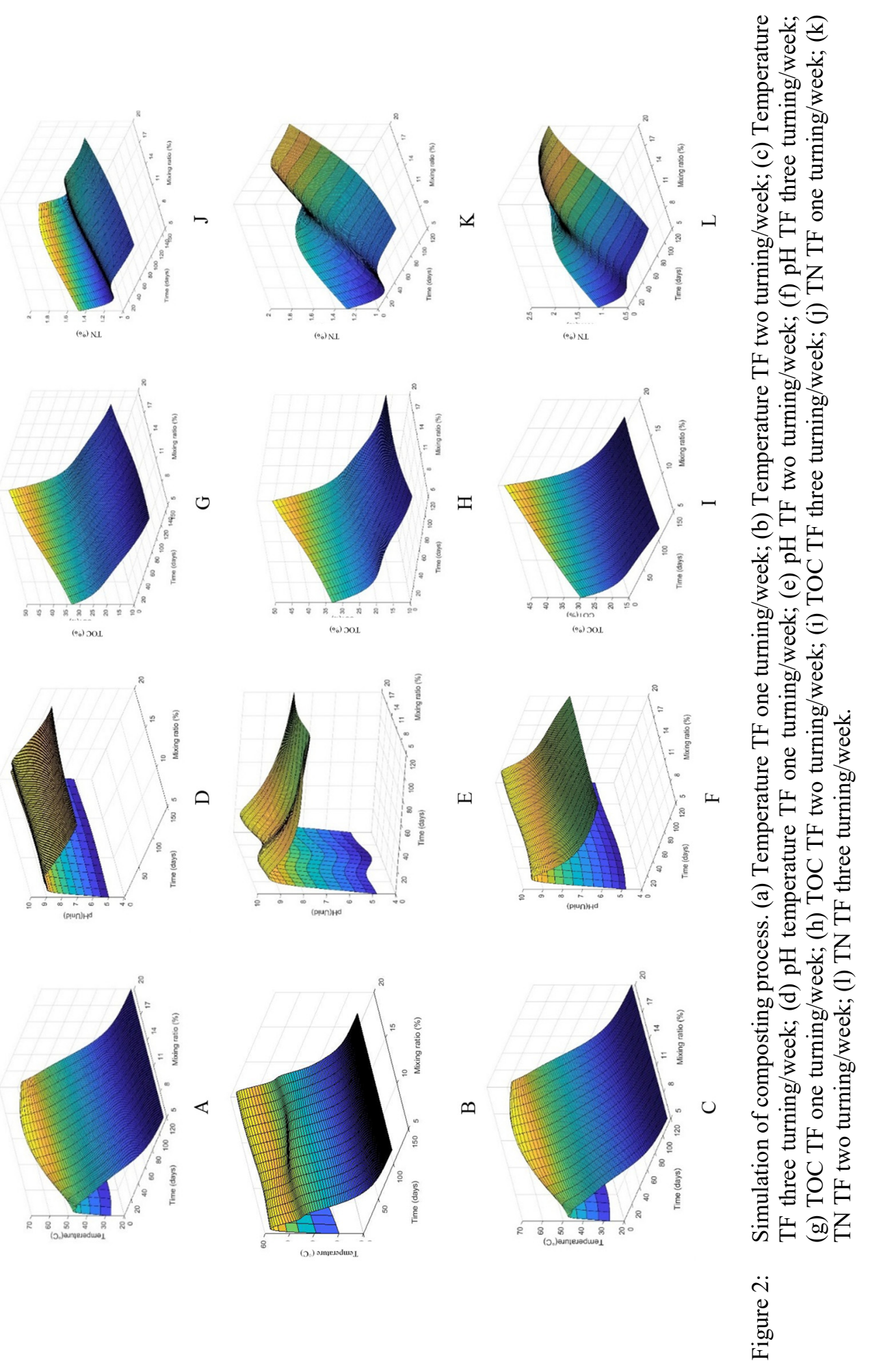


The variation of TOC (Fig. 2(g)-(i)) indicates the relative decrease of content of these parameter during the composting process. Consistent with the temperature profiles, the highest degradation of TOC during the active phase of process was with the highest TF; which agrees with the results of studies previously reported [36]. This is associated with a greater availability of oxygen product of the applied turning and of exposure of fresh material to biodegrade by microorganisms [26], [31]. It was observed that TF of two turning/week positively influences the degradation and is greater than that observed with $\mathrm{TF}$ of one turning/week.

The highest percentage of degradation (55\%) was achieved for a $28 \%$ MR in TF of three turning/week, followed by a MR of $26 \%$ in TF of two turning/week (47\%) and $29 \%$ in TF of one turning/week (41\%). A similar behavior in OM was also observed by Tiquia [16]. A despite, regions in TF3 with MR between 27 and 29 and TF between 24 and 26 are presented where the degradation curves are more pronounced with respect to PM between 25 and 29 in $\mathrm{TF}$ one turning/week; this shows correspondence to what was indicated by Oviedo Ocana et al. [26]. In the case of the highest MR (30), the higher carbon content seems to promote OM losses throughout composting.

The lowest TOC content was observed for MR lower than 15\%, possibly because of the emission of $\mathrm{CO}_{2}$ (Fig. 2(g)-(i)). Less significant changes were observed in the degradation of TOC after 50 days of processing; for all MR, MO losses tended to stabilize at the end of the composting process that could be attributed to the consumption of slowly biodegradable compounds such as lignin and hemicellulose. The lowest values of TOC at the end of the process corresponded to MR between 10 and $15 \%$ for TF of one turning/week $(<14 \%)$, which is associated with low $\mathrm{C} / \mathrm{N}$ ratios promote greater carbon losses [37]. In contrast, the content of TOC was higher in PM between 18 and $24 \%$ for a TF of two turning/week ( $\geq 20 \%)$. However, the TOC values obtained from the simulation are higher compared to those reported in previous studies by other researchers. This can be associated that both the star grass and the filter cake provide a high MO content and contribute organic compounds such as cellulose, hemicellulose and lignin [13], [26].

Fig. 2(j)-(1) show the changes in the TN for the TF and MR considered. The highest TN losses (12-16\%) was observed in TF of one and three turning/week with MR between 10 and $20 \%$ compared to TF of two turning/week with MR greater than $13 \%$ during the first 22 days of the process. This fact could be explained considering that an insufficient supply of air to the microorganisms by compaction of the pile (TF one turning/week), promotes the volatilization of $\mathrm{NH}_{3}$ and $\mathrm{H}_{2} \mathrm{~S}$. In contrast, the increase in the frequency of aeration (TF three turning/week) generally influences the volatilization of $\mathrm{NH}_{3}$ as reported by several researchers [13], [38]. Consequently, TF had a significant effect $(\mathrm{p} \leqslant 0.05)$ on nitrogen behavior over time. It was observed that MR of the order of 10 and $14 \%$ for TF of one turning peer week, presented the highest loss of TN (16\%), followed by MR between 26 and $29 \%$ in TF of three turning/week (14\%), while treatments with MR between 23 and $25 \%$ in TF of two turning/week had the lowest (11\%). During the cooling phase ( $>45$ days), it was observed that TN content begins to increase in all treatments. MR between 25 and $30 \%$ had the highest concentration of nitrogen at the end of the process $(>2 \%)$ compared to other operational conditions. This is associated with the mineralization effect of MO [13].

The results found with the simulation of the process reveal that in the content of TOC, TN and $\mathrm{pH}$, the product with TF of two turning/week and MR between 22 and $28 \%$ has potential to be used as a soil improver in agriculture and that meets quality standards (Australian Standard, Guideline of The Fertilizer Order 1985; NCh2880). 


\section{PCONCLUSIONS}

In this research, the mathematical models obtained with the neural networks were effective in predicting the behavior of the parameters of interest in the biowaste composting process with FC and SG. In addition, the modeling approach of neural network can be further applied in other studies of dynamic systems modeling because it is generalized in a straightforward manner to almost any scenario. However, this methodology must be validated in other contexts.

The thermophile stage is the stage in which the highest rates of degradation of the substrate and co-substrates occur, due to the influence of temperature on the kinetics of the process. In addition, it was found that the process is affected dynamically and significantly by the factors considered (TF and MR).

In this research it was evidenced that the composting process under different mixing ratios and different turning frequencies (TF) affects the quality of final product, being the MR 60:20:20 and 65:15:20, with TF of two turning/week and an approximate operating time of 75 days, the conditions that allow obtaining a final product of acceptable physical-chemical quality according to different national and international quality standards; However, the need to carry out optimization studies where several response parameters are considered to find the best region that maximizes the quality of the product from the agricultural perspective is highlighted.

\section{FUTURE DEVELOPMENTS}

The future development is in the optimization of the process and quality of the product combining ANN and metaheuristic methods as particle swarm optimization (PSO). This will allow co-composting to be considered as a non-linear multidimensional problem, where the aim is to maximize the quality of the product in a shorter process time.

\section{ACKNOWLEDGEMENTS}

The authors thank the University of Valle for funding the research project titled "Potencial de valorización energetica y agrícola a partir de la fracción orgánica de residuos sólidos urbanos CI 2962" and COLCIENCIAS for supporting Jonathan Soto Paz through a national doctorate fellowship. Oviedo-Ocaña thanks the Universidad Industrial de Santander for the support in the writing of this manuscript.

\section{REFERENCES}

[1] Aalok, A., Tripathi, A. \& Soni, P., Vermicomposting: A better option for organic solid waste management. Journal of Human Ecology, 24(1), pp. 59-64, 2008.

DOI: $10.1080 / 09709274.2008 .11906100$.

[2] Thi, N., Kumar, G. \& Lin, C.-Y., An overview of food waste management in developing countries: Current status and future perspective. Journal of Environmental Management, 157, pp. 220-229, 2015.

[3] Faverial, J., Boval, M., Sierra, J. \& Sauvant, D., End-product quality of composts produced under tropical and temperate climates using different raw materials: A metaanalysis. Journal of Environmental Management, 183, 909-916, 2016.

DOI: 10.1016/j.jenvman.2016.09.057.

[4] Götze, R., Boldrin, A., Scheutz, C. \& Astrup, T.F., Physico-chemical characterisation of material fractions in household waste: Overview of data in literature. Waste Management, 49, pp. 3-14, 2016. DOI: 10.1016/j.wasman.2016.01.008. 
[5] Noguera, K. \& Olivero, J., Los rellenos sanitarios en Latinoamérica: Caso colombiano. Revista de la Academia Colombiana de Ciencias Exactas, Físicas y Naturales, 34, pp. 347-356, 2010.

[6] De Feo, G., De Gisi, S. \& Williams, I.D., Public perception of odour and environmental pollution attributed to MSW treatment and disposal facilities: A case study. Waste Management, 33(4), pp. 974-987, 2013.

DOI: 10.1016/j.wasman.2012.12.016.

[7] Saer, A., Lansing, S., Davitt, N.H. \& Graves, R.E., Life cycle assessment of a food waste composting system: Environmental impact hotspots. Journal of Cleaner Production, 52, pp. 234-244, 2013. DOI: 10.1016/j.jclepro.2013.03.022.

[8] Bernstad Saraiva Schott, A., Wenzel, H. \& La Cour Jansen, J., Identification of decisive factors for greenhouse gas emissions in comparative life cycle assessments of food waste management - An analytical review. Journal of Cleaner Production, 119, pp. 13-24, 2016. DOI: 10.1016/j.jclepro.2016.01.079.

[9] Hanserud, O.S., Cherubini, F., Øgaard, A.F., Müller, D.B. \& Brattebø, H., Choice of mineral fertilizer substitution principle strongly influences LCA environmental benefits of nutrient cycling in the agri-food system. Science of the Total Environment, 615, pp. 219-227, 2018. DOI: 10.1016/j.scitotenv.2017.09.215.

[10] Onwosi, C.O. et al., Composting technology in waste stabilization: On the methods, challenges and future prospects. Journal of Environmental Management, 190, pp. 140157, 2017. DOI: 10.1016/j.jenvman.2016.12.051.

[11] Cerda, A., Artola, A., Font, X., Barrena, R., Gea, T. \& Sánchez, A., Composting of food wastes: Status and challenges. Bioresource Technology, 248(Pt A), pp. 57-67, 2017.

[12] Soto-Paz, J., Oviedo-Ocaña, R., Marmolejo-Rebellón, L.F. \& Manyoma-Velásquez, P.C., Compostaje de biorresiduos: Tendencias de investigación y pertinencia en países en desarrollo. DYNA, 84(203), pp. 334-342, 2017.

DOI: 10.15446/dyna.v84n203.61549.

[13] Bryndum, S., Muschler, R., Nigussie, A., Magid, J. \& de Neergaard, A., Reduced turning frequency and delayed poultry manure addition reduces $\mathrm{N}$ loss from sugarcane compost. Waste Management, 65, pp. 169-177, 2017.

DOI: 10.1016/j.wasman.2017.04.001.

[14] Oviedo, R., Marmolejo, L. \& Torres, P., Advances in research on biowaste composting in small municipalities of developing countries. Lessons from Colombia. Revista Ingenieria Investigacion y Tecnologia, 18(1), pp. 31-42, 2017.

DOI: $10.22201 /$ fi.25940732e.2017.18n1.003.

[15] Kurola, J.M., Arnold, M., Kontro, M.H., Talves, M. \& Romantschuk, M., Wood ash for application in municipal biowaste composting. Bioresource Technology, 102(8), pp. 5214-5220, 2011. DOI: 10.1016/j.biortech.2011.01.092.

[16] Tiquia, S., Reduction of compost phytotoxicity during the process of decomposition. Chemosphere, 79(5), pp. 506-512, 2010. DOI: 10.1016/j.chemosphere.2010.02.040.

[17] Awasthi, M.K., Pandey, A.K., Khan, J., Bundela, P.S., Wong, J.W. \& Selvam, A., Evaluation of thermophilic fungal consortium for organic municipal solid waste composting. Bioresource Technology, 168, pp. 214-221, 2014.

DOI: 10.1016/j.biortech.2014.01.048.

[18] Kumar, M., Ou, Y.-L. \& Lin, J.-G., Co-composting of green waste and food waste at low C/N ratio. Waste Management, 30(4), pp. 602-609, 2010.

DOI: 10.1016/j.wasman.2009.11.023. 
[19] Iqbal, M.K., Nadeem, A., Sherazi, F. \& Khan, R.A., Optimization of process parameters for kitchen waste composting by response surface methodology. International Journal of Environmental Science and Technology, 12(5), pp. 17591768, 2015. DOI: 10.1007/s13762-014-0543-x.

[20] Fernando, H. \& Surgenor, B., An unsupervised artificial neural network versus a rulebased approach for fault detection and identification in an automated assembly machine. Robotics and Computer-Integrated Manufacturing, 43, pp. 79-88, 2017. DOI: 10.1016/j.rcim.2015.11.006.

[21] Boem, F., Ferrari, R.M., Keliris, C., Parisini, T. \& Polycarpou, M.M., A distributed networked approach for fault detection of large-scale systems. IEEE Transactions on Automatic Control, 62, pp. 18-33, 2017.

[22] Sakurai, K., Método sencillo del análisis de residuos sólidos, HDT 17. CEPIS. Online. www.cepis.ops-oms.org/eswww/proyecto/repidisc/publica/hdt/hdt017.html. Accessed on: 6 Jun 2018, 2001.

[23] APHA, AWWA \& WEF, Standard methods for examination of water and wastewater. A.W.W.A. American Water Works Association and Water Environment Federation, ed. Water Environment Federation, 22nd ed., Washington, DC, 2012.

[24] ICONTEC, Norma Técnica Colombiana 5167. Productos para la Industria Agrícola, Productos Orgánicos Usados como Abonos o Fertilizantes y Enmiendas de Suelo, 2004.

[25] Li, Z., Lu, H., Ren, L. \& He, L., Experimental and modeling approaches for food waste composting: A review. Chemosphere, 93(7), pp. 1247-1257, 2013.

DOI: 10.1016/j.chemosphere.2013.06.064.

[26] Oviedo Ocana, E.R., Marmolejo Rebellón, L.F. \& Torres Lozada, P., Influencia de la frecuencia de volteo para el control de la humedad de los sustratos en el compostaje de biorresiduos de origen municipal. Revista Internacional de Contaminación Ambiental, 30, pp. 91-100, 2014.

[27] Yildiz, S. \& Degirmenci, M., Estimation of oxygen exchange during treatment sludge composting through multiple regression and artificial neural networks (estimation of oxygen exchange during composting). International Journal of Environmental Research, 9, pp. 1173-1182, 2015.

[28] Wang, J. \& Wan, W., Optimization of fermentative hydrogen production process using genetic algorithm based on neural network and response surface methodology. International Journal of Hydrogen Energy, 34(1), pp. 255-261, 2009.

DOI: $10.1016 / j$.ijhydene.2008.10.010.

[29] Bhattacharjee, N.V.\& Tollner, E.W., Improving management of windrow composting systems by modeling runoff water quality dynamics using recurrent neural network. Ecological Modelling, 339, pp. 68-76, 2016. DOI: 10.1016/j.ecolmodel.2016.08.011.

[30] Ogunwande, G.A., Osunade, J.A., Adekalu, K.O. \& Ogunjimi, L.A.O., Nitrogen loss in chicken litter compost as affected by carbon to nitrogen ratio and turning frequency. Bioresource Technology, 99(16), pp. 7495-7503, 2008.

DOI: 10.1016/j.biortech.2008.02.020.

[31] El Kader, N.A., Robin, P., Paillat, J.-M. \& Leterme, P., Turning, compacting and the addition of water as factors affecting gaseous emissions in farm manure composting. Bioresource Technology, 98(14), pp. 2619-2628, 2007.

DOI: 10.1016/j.biortech.2006.07.035.

[32] Guidoni, L.L.C. et al., Home composting using different ratios of bulking agent to food waste. Journal of Environmental Management, 207, pp. 141-150, 2018.

DOI: 10.1016/j.jenvman.2017.11.031. 
[33] Kalemelawa, F. et al., An evaluation of aerobic and anaerobic composting of banana peels treated with different inoculums for soil nutrient replenishment. Bioresource Technology, 126, pp. 375-382, 2012. DOI: 10.1016/j.biortech.2012.04.030.

[34] Tognetti, C., Mazzarino, M. \& Laos, F., Comprehensive quality assessment of municipal organic waste composts produced by different preparation methods. Waste Management, 31(6), pp. 1146-1152, 2011. DOI: 10.1016/j.wasman.2010.12.022.

[35] Hemidat, S., Jaar, M., Nassour, A. \& Nelles, M., Monitoring of composting process parameters: A case study in Jordan. Waste and Biomass Valorization, pp. 1-18, 2018.

[36] Getahun, T., Nigusie, A., Entele, T., Gerven, T.V. \& Bruggen, B.V.D., Effect of turning frequencies on composting biodegradable municipal solid waste quality. Resources, Conservation and Recycling, 65, pp. 79-84, 2012.

DOI: 10.1016/j.resconrec.2012.05.007.

[37] Waqas, M., Nizami, A.S., Aburiazaiza, A.S., Barakat, M.A., Ismail, I.M.I. \& Rashid, M.I., Optimizing the process of food waste compost and valorizing its applications: A case study of Saudi Arabia. Journal of Cleaner Production, 176, pp. 426-438, 2018. DOI: $10.1016 /$ j.jclepro.2017.12.165.

[38] Guo, R. et al., Effect of aeration rate, $\mathrm{C} / \mathrm{N}$ ratio and moisture content on the stability and maturity of compost. Bioresource Technology, 112, pp. 171-178, 2012.

DOI: 10.1016/j.biortech.2012.02.099. 